\title{
Pregnancy in Patients Under 16 Years
}

\author{
B. VICTOR LEWIS,* M.B., F.R.C.S.ED., M.R.C.o.G. ; PETER JAMES NASH $\dagger$
}

Brit. med.F., 1967, 2, 733-734

From 1 January 1963 until 31 September 1966102 primigravidae and one multigravida patient under the age of 16 at conception were delivered in the obstetric unit of St. Helier Hospital, Carshalton. Thirty-three of these patients were booked from a home for pregnant schoolgirls in North Surrey, the remainder being referred from the district general practitioners. During this period a total of 8,366 deliveries were carried out; the incidence of pregnancy in young patients was thus $1.2 \%$. The youngest patient was aged 11 years and 9 months at conception and the oldest 15 years and 11 months (Table I). The multigravid patient conceived at 13 years 6 months and 15 years 7 months.

TABLE I.-Pregnancy in 103 Patients Under the Age of 16 at Conception

\begin{tabular}{ll|c|c|c|c|c}
\hline Age &.. & $11-12$ & $12-13$ & $13-14$ & $14-15$ & $\begin{array}{c}15-16 \\
\text { No. }\end{array}$ \\
\hline
\end{tabular}

Antenatal Care.-Fifty-four patients were seen on at least one occasion before the 28th week of gestation, while a further 46 were referred for antenatal care in the last trimester. The remaining three cases were admitted unbooked in early labour. The Wassermann reaction was negative in all cases.

Method of Delivery (Table II).-All but four patients delivered vaginally, the majority without operative intervention. The forceps rate was $10 \%$, and was approximately equal to the overall hospital forceps rate of $11.5 \%$. There was one vacuum extraction. The caesarean section rate was $3.9 \%$, compared with $6.5 \%$ for the hospital during the period under review. All four caesarean sections were the lower segment procedure

\begin{tabular}{|c|c|c|c|c|c|}
\hline \multirow{2}{*}{ Age } & \multicolumn{5}{|c|}{ Method of Delivery - } \\
\hline & O.A. & O.P. & $\begin{array}{l}\text { Forceps } \\
\text { and V.E. }\end{array}$ & Breech & L.S.C.S. \\
\hline $\begin{array}{l}11-12 \\
13-14 \\
14-15 \\
15-16\end{array}$ & $\begin{array}{r}8 \\
29 \\
44\end{array}$ & $\begin{array}{l}1 \\
1 \\
4\end{array}$ & $\begin{array}{l}5 \\
6\end{array}$ & 1 & $\begin{array}{l}1 \\
1 \\
2\end{array}$ \\
\hline Total & 81 & 6 & 11 & 1 & 4 \\
\hline
\end{tabular}

carried out after a trial of labour. Three of the labours were terminated for cephalo-pelvic disproportion after first stages lasting 26, 30, and 34 hours, while the fourth section was performed at almost full dilatation with the head engaged because of foetal distress.

There were no stillbirths and only one neonatal death, in a 15-year-old induced at term because of persistent albuminuria with a normal blood pressure. After a six-hour labour there occurred the spontaneous delivery of a 2,500-g. infant, which died on the fifth day with multiple congenital abnormalities.

TABLE III.-Length of First Stage of Labour in 99 Young Patients Delivered Vaginally and 99 Controls. Control Group were Primigravidae Between the Ages of 18 and 35 Chosen at Random

\begin{tabular}{c|c|c|c|c|c|c}
\hline Time (hours): & $0-6$ & $6-12$ & $12-24$ & $24-36$ & $36-48$ & $48+$ \\
\cline { 1 - 4 } Young patients & 37 & 31 & 24 & 5 & 2 & 0 \\
Controls & 13 & 34 & 35 & 10 & 4 & 3
\end{tabular}

Length of Labour.-Labour was characterized by the ease with which full dilatation was achieved, 68 patients reaching the second stage within 12 hours (Table III). In only two cases was the first stage prolonged beyond 36 hours. No special difficulties were met with in the second stage, and delivery

TABLE IV.-Length of Second Stage of Labour in 99 Young Patients and

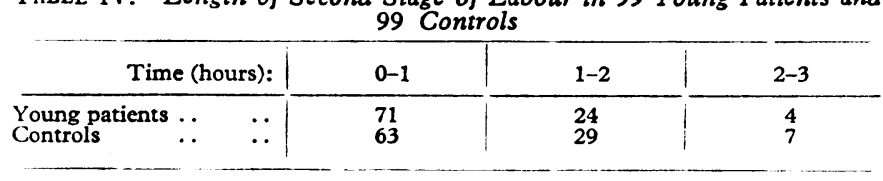

TABLE V.-Weights of Babies of 99 Young Patients and 99 Controls

\begin{tabular}{rr|c|c|c|c|c}
\multicolumn{2}{r|}{ Weight (g.): } & $<2,500$ & 2,500 & 3,000 & 3,500 & $4,000+$ \\
\hline \begin{tabular}{rr|r|r|r} 
Young patients \\
Controls
\end{tabular} & $\cdots$ & 6 & 28 & 39 & 20 & 6 \\
\end{tabular}

within one hour usually occurred (Table IV). The ease of labour was not related to the size of the baby (Table V).

The heights of all patients were plotted on a standard chart relating height to age as prepared by Tanner (1958). The older patients were grouped around the fiftieth percentile, indicating that most were of average height for their ages. The younger patients were above average height. Nine of the 1013 -year-olds were found to be above the seventy-fifth percentile when their heights were plotted at age 13, and above the fiftieth percentile when plotted at age 14 .

Pre-eclampsia.-This was defined as hypertension above 140/ $90 \mathrm{~mm}$. Hg with or without oedema and albuminuria in the last trimester of pregnancy. With these criteria 21 patients $(20 \%)$ had pre-eclampsia. There were no perinatal deaths in this group, but only three cases could be classified as severe, the blood pressure rising above $160 / 100 \mathrm{~mm}$. Hg. One of these patients had two eclamptic fits shortly after spontaneous vaginal delivery of a living male infant. She was booked at the age of 13 and subsequently admitted to hospital with pre-eclampsia. The eclamptic fits were controlled with bromethol (Avertin), but before recovery an anxious 12 hours followed during which a respirator was in continuous use.

\section{Discussion}

Pregnancy in young patients has been discussed on several occasions, mainly in the American literature. The only recent review in the British literature is that of Stearn (1963), who presented a series of 30 patients, delivered in the South London area, and emphasized the speed of labour and ease of delivery. There were no caesarean sections even though $17 \%$ of his patients delivered infants weighing over $4,000 \mathrm{~g}$. and in 16 cases the head failed to engage until the onset of labour.

Low caesarean section rates have been reported by several writers: Briggs et al. (1962), 3.5\%; Hacker et al. (1952), $1.5 \%$; Marchetti and Menaker (1950), $0.6 \%$; and Claman and Bell (1964) less than $1 \%$.

\footnotetext{
* Senior Registrar, Institute of Obstetrics and Gynaecology, and St. Helier † R.A.F. ; Medical Student, Sheffield University.
} 
Hassan and Falls (1964) pointed out that the incidence of caesarean section for cephalo-pelvic disproportion tended to rise in the very young patients, and quoted an incidence of $7.6 \%$ in 26 patients. Since the pelvic bones tend to fuse around the time of puberty, there can be little alteration in the pelvic measurements once the menarche has occurred. Moreover, the general standard of nutrition has improved considerably since the war years, and the average height has tended to rise. In the present series most of the patients were scattered about the mean on standard growth charts, while the younger patients were noticeably taller than average.

Pre-eclampsia is a definite hazard in this group of patients, the incidence in 103 cases being $20 \%$. Nearly all the cases were quite mild and settled well with bed rest and sedation. There was one case of eclampsia, but no stillbirths or neonatal deaths. These figures are similar to those of Claman and Bell (1964) and Marchetti and Menaker (1950), who reported the incidence of pre-eclampsia at 18 and $19.7 \%$ respectively. In the recent British series Stearn (1963) found 8 patients out of 30 in whom the blood pressure rose to $140 / 90 \mathrm{~mm}$. Hg.

Vaginal delivery presented very few difficulties, and $37 \%$ of patients were delivered within six hours of the onset of labour. This compares with the rate of $13 \%$ for the control group. Six of the 11 operative deliveries were by low forceps, and there were four mid-cavity rotations and extractions from posterior positions.

\section{Summary}

Pregnancy and labour have been considered in 103 patients under the age of 16 at the time of conception. The ages ranged from 11 years and 9 months to 15 years and 11 months. There was one multigravid patient.

The incidence of pre-eclampsia was considerably increased, but the perinatal mortality rate was $1 \%$ for the whole group. Easy spontaneous vaginal delivery was the rule. The forceps rate was $10 \%$ and the caesarean section rate $4 \%$.

Though pregnancy in young patients presents grave sociological problems, pregnancy and labour usually proceed without difficulty. The greatest hazard is pre-eclampsia.

We should like to thank Miss Doreen Daley and the consultant staff of St. Helier Hospital for allowing us access to case records and for helpful advice and criticism.

\section{REFERENCES}

Briggs, R. M., Herren, R. R., and Thompson, W. B. (1962). Amer. F.

Obstet. Gynec., 84, 436. .

Hacker, E. M., Epperson, J. W. W., Priddle, H. D., and Longyear, H. W. (1952). Ibid., 64, 644.

Hassan, H. M., and Falls, F. H. (1964). Ibid., 88, 256.

Marchetti, A. A., and Menaker, J. S. (1950). Ibid., 59, 1013.

Stearn, R. H. (1963). Lancet, 2, 1083.

Tanner, J. M. (1958). In Modern Trends in Paediatrics, edited by A Holzel and J. P. M. Tizard, 2nd series, p. 325 . London.

\title{
Obstetrical Implications of Pregnancy in Primigravidae Aged 16 Years or Less
}

\author{
WULF. H. UTIAN, ${ }^{*}$ M.B., B.CH.
}

Brit. med. F., 1967, 2, 734-730

Teenage marriage is on the increase (Brit. med. F., 1965). Although pregnancy before the age of 16 is rather uncommon, the incidence is rising (Clough, 1958). About $8 \%$ of all births are to women in the teenage group (Brit. med. F., 1965). The problems that may arise are both social and obstetrical. In this study attention has been confined to the obstetrical aspect.

In the past 15 years over 20 studies of pregnancy and labour in young primigravidae have been published. Unfortunately, most of these have been based on different age levels, different racial groups, and different diagnostic criteria for pregnancy syndromes. There has, moreover, been little study on young primigravidae of European origin, and there would appear to be particular need for more information regarding pregnancy in this group.

\section{Present Study}

During the six-year period, 1 January 1960 to 28 February 1966, 100 white primigravid patients of English and Dutch descent aged 16 or less were managed at the Mowbray Maternity Hospital in Cape Town. A large proportion of these cases were admitted from two institutions which care for unmarried mothers. This group is here called the "study group." A series of 100 consecutive white patients aged 22, delivered during a corresponding period, is termed the " control group." No distinction was made as to social class in this series, but the

\footnotetext{
- Registrar in Obstetrics, University of Cape Town and Groote Schuur
} Hospital, Cape Town. majority of these patients were of the lower-to-middle class income group (Classes II-III).

The study group comprised one patient aged 13,9 aged 14, 21 aged 15, and 69 aged 16. As the numbers were relatively small, the 13- to 16-year-olds were compared as a group with the 22-year-olds.

Thirty-two per cent. of the study group were married as against $78 \%$ of the control group.

The adequacy of antenatal care was not easy to assess. Ninety-four per cent. of both groups were seen at antenatal clinics on three or more occasions.

\section{Factors in Pregnancy}

Toxaemia of Pregnancy.-Pre-eclamptic toxaemia was defined in this study as a blood pressure of $140 / 90 \mathrm{~mm} . \mathrm{Hg}$ or higher after 24 weeks and proteinuria. The incidence was $21 \%$ in the study group and $12 \%$ in the control group. There was one case of eclampsia in the study group and none in the control group. Unclassified toxaemia was found in $15 \%$ of the study group-for example, these patients showed hypertension without either proteinuria or oedema. The incidence was only $5 \%$ in the control group. The overall picture was thus $36 \%$ in the study group and only $17 \%$ in the control group. There were three cases of accidental haemorrhage (abruptio placentae) in the study group and none in the controls. Of these cases, two resulted in premature labour, one premature infant being stillborn. The third case was a minor 